\title{
An observational study of fetomaternal outcome in euthyroid women with anti-thyroid peroxidase antibodies at tertiary care hospital
}

\author{
Harendra K. Netra, Reena Pant*, Krishna P. Banerjee
}

Department of Obstetrics and Gynecology, SMS Medical College, Jaipur, Rajasthan, India

Received: 22 February 2020

Revised: 01 March 2020

Accepted: 27 March 2020

\author{
*Correspondence: \\ Dr. Reena Pant, \\ E-mail: pant.dr.reena@gmail.com
}

Copyright: (c) the author(s), publisher and licensee Medip Academy. This is an open-access article distributed under the terms of the Creative Commons Attribution Non-Commercial License, which permits unrestricted non-commercial use, distribution, and reproduction in any medium, provided the original work is properly cited.

\begin{abstract}
Background: Several changes are observed in maternal thyroid function during pregnancy and failure to adapt to these physiological changes results in thyroid dysfunction, especially if complicated by the presence of thyroid antibodies. The presence of TPO-Ab is associated with increased rate of pregnancy complications such as miscarriage, preterm delivery, placental abruption, pregnancy-induced hypertension, intrauterine death and low birth weight. Objective of this study was to study the effect of anti-TPO Ab positivity on pregnancy outcome and estimate the prevalence of anti-TPO Ab in euthyroid obstetric women.

Methods: This observational study enrolled 500 euthyroid pregnant women, age 20-35 years, up to 20 weeks gestation. Venous blood samples collected and analyzed for the anti TPO Ab levels. On the basis of anti TPO Ab positivity they were divided into two groups, anti-TPO Ab positive and Ab negative group. These two groups were followed up till delivery or abortion and compared for maternal and fetal outcomes.

Results: Prevalence of anti-TPO antibody positivity was 5.2\% in euthyroid obstetric women. Most of anti-TPO Ab positive women were overweight. There were higher numbers of miscarriage (11.54\%) in anti-TPO Ab positive euthyroid pregnancies than $(2.53 \%)$ in antibody negative women. Incidence of low birth weight babies was 4-fold higher in anti-TPO Ab positive women. More than two-fold increase in incidence of placental abruption in anti-TPO Ab positive women. Parity, anaemia, gestational hypertension, preeclampsia, GDM, PROM, PPH, low Apgar scores, NICU admission, IUD and neonatal death were not significantly associated with anti-TPO Ab positivity.

Conclusions: Anti TPO Ab positivity significantly associated with pre-pregnancy BMI, miscarriage rates and low birth weight of newborns.
\end{abstract}

Keywords: Anti-thyroid peroxidase antibodies, Euthyroid, Pregnancy outcome

\section{INTRODUCTION}

During pregnancy various physiological and biochemical changes take place to meet the metabolic demand of the developing fetus. Several changes are observed in maternal thyroid functions during pregnancy and failure to adapt to these physiological changes results in thyroid dysfunction, especially if complicated by the presence of thyroid antibodies. ${ }^{1}$
During $1^{\text {st }}$ trimester, the fetus completely depends on transplacental passage of maternal thyroxine, as fetal thyroid gland is non-functional during this period.

So, normal maternal thyroid functions are important for fetal development. About 2-5\% of pregnant women suffer from thyroid disorders and timely intervention can be done if detected early. ${ }^{2}$ In iodine sufficient areas the most common cause of both hypo and hyperthyroidism is 
autoimmune thyroiditis. Hashimoto's thyroiditis (most common organ specific autoimmune disease) being the most common cause for hypothyroidism and Grave's disease accounts for more than $85 \%$ cases of hyperthyroidism. Subclinical hypothyroidism shows no clinical symptoms but over half of them show evidence of auto immune thyroid disease. Approximately $10 \%$ euthyroid pregnant women show anti TPO Abs at 14 weeks of gestation and some of them present as subclinical hypothyroidism. ${ }^{3}$

A wide range of cut-off values (15 to 143 IU/L) are used to define TPO Ab positivity. A number of etiologies that have been hypothesized are: (1) thyroid autoantibodies may be considered as a marker of generalized autoimmune dysfunction, responsible for an increased pregnancy loss; (2) TPO Ab positive euthyroid women before pregnancy are more prone to develop subclinical or overt hypothyroidism during pregnancy due to hormonal imbalance particularly in first trimester; (3) thyroid autoimmunity is a risk factor for infertility; (4) thyroid autoantibodies acting directly on the placenta or the fertilized ovum cause rejection and (5) women with thyroid autoantibodies become pregnant at an older age, hence with an increased risk. The presence of anti-TPO Abs is associated with increased rate of pregnancy complications such as miscarriage, preterm delivery, placental abruption, PIH, intrauterine death (IUD), IUGR and low birth weights. 4 So, TPO-Ab screening test can be an important routine diagnostic tool in early pregnancy which can help to identify women at risk for poor fetomaternal outcome. There is little work known on this regard in this study setup. So, this study has been undertaken which can be helpful to obstetricians to take necessary steps in euthyroid pregnant women with TPOAb positivity.

Objectives was to study the effect of anti-thyroid peroxidase antibodies (anti-TPO Ab) positivity on pregnancy outcome in euthyroid women and to estimate and evaluate the prevalence of anti-TPO Ab.

\section{METHODS}

This hospital based descriptive type of observational prospective study was conducted at department of obstetrics and gynecology, SMS Medical College, Jaipur during June 2018 to September 2019 after ethical clearance from study institutional review board and ethical committee, 500 euthyroid pregnant women up to 20 weeks gestation between ages 20-35 years were selected as sample size in present study after applying inclusion and exclusion criteria. All participants underwent a comprehensive medical evaluation including a detailed history and a thorough physical examination.

\section{Inclusion criteria}

- A 20 to 35 years aged euthyroid women with singleton pregnancy up to 20 weeks of gestation including women who were already in process of abortion

- Women giving informed and written consent.

\section{Exclusion criteria}

- Pregnancy with known autoimmune disorders

- Cervical incompetence or any uterine malformations

- Any chronic systemic illness or critical medical illness during pregnancy

- History of thyroid surgery or taking any known thyroid treatments.

Serum thyroid stimulating hormone (TSH), T3 and free T4 was measured in selected pregnant women to ascertain hypothyroid, hyperthyroid or euthyroid status of women. Euthyroid women were selected as study participants. Women diagnosed with abnormal thyroid functions were referred to endocrinology department for treatment. After that $5 \mathrm{ml}$ of venous blood was collected in plain vial from euthyroid women and analysed for antiTPO Ab levels by electro-chemiluminescence immunoassay with "Immulite 2000 Advia Centaur XP machine" in the central lab (normal value $<60 \mathrm{IU} / \mathrm{ml}$ ). Analytic sensitivity of above assay is $5 \mathrm{IU} / \mathrm{ml}$ with a clinical sensitivity and specificity of $98.6 \%$ and $98.5 \%$ respectively.

There were wide variations of reference ranges used in different studies. So, in this study trimester and method specific $\mathrm{TSH}$, free $\mathrm{T} 4$ and free $\mathrm{T} 3$ values were taken as references as per American thyroid association (ATA) 2017 (Table 1).

On the basis of anti-TPO Ab positivity (>60 IU/ml), cases were divided into two groups:

- Group A- Anti-TPO Ab positive cases and

- Group B- Anti-TPO Ab negative cases.

Following parameters were noted in both groups: age, demographic and socioeconomic status, menstrual history, obstetric history, body mass index (BMI), antenatal investigations and fetomaternal outcomes. Women were followed up till delivery or abortion. Data was recorded in a predesigned proforma and maternal and fetal outcomes were noted in both the groups and statistically analysed by using unpaired t-test for continuous variables while chi-square for normal categorical variables.

\section{Pregnancy outcome noted as}

Anaemia, gestational hypertension, preeclampsia, gestational diabetes mellitus, placental abruption, PPH, preterm delivery- early preterm ( $<34$ weeks) or late preterm (34 to 37 weeks), Premature rupture of membranes, meconium and mode of delivery-vaginal delivery or caesarean section. 
Table 1: Reference values as per American thyroid association guidelines-2017.

\begin{tabular}{|llll|}
\hline Reference range & First trimester & Second trimester & Third trimester \\
\hline TSH $(\mathrm{mIU} / \mathrm{L})$ & $0.1-2.5$ & $0.2-3.0$ & $0.3-3.0$ \\
\hline Free $\mathrm{T} 4(\mathrm{ng} / \mathrm{dL})$ & $0.8-1.2$ & $0.6-1.0$ & $0.5-0.8$ \\
\hline Free T3 $(\mathrm{pmol} / \mathrm{L})$ & $8.04-22$ & $9.26-22.12$ & $9.54-27.02$ \\
\hline
\end{tabular}

\section{Neonatal outcome noted as}

Miscarriage, Intra uterine death, Apgar score at 1 minute, birth weight, NICU admission and neonatal death.

\section{RESULTS}

In this study, 26 women were found to be anti-TPO Ab positive and 474 were found $\mathrm{Ab}$ negative, hence the prevalence of anti-TPO Ab positivity in euthyroid women were $5.20 \%$. Among anti-TPO Ab positive group, 12 $(46.15 \%)$ women and among $\mathrm{Ab}$ negative group, 190 $(40.08 \%)$ women were seen in 24-27 years age group with mean maternal age $24.96 \pm 3.13$ years and $24.86 \pm 3.97$ years, respectively. No correlation was observed between age and anti-TPO Ab positivity $(\mathrm{p}=0.901)$. The association of residence, religion and socio-economic class with anti-TPO Ab positivity is not significant. Most of women were multigravida, $61.54 \%$ versus $60.34 \%$ respectively in anti-TPO $\mathrm{Ab}$ positive and negative groups.

Authors found a significant association ( $\mathrm{p}=0.000$, $X^{2}=21.819$ and d.f.=3) between pre-pregnancy body mass index and anti-TPO Ab positivity. Most of anti-TPO Ab positive women were overweight $(\mathrm{BMI}=25$ to 29.9) while most of $\mathrm{Ab}$ negative women had normal weight (BMI=18.5 to 24.9).

Authors observed higher prevalence of anaemia (57.69\% versus $49.58 \%)$, gestational hypertension $(7.69 \%$ versus $6.75 \%)$ and placental abruption $(3.85 \%$ versus $1.68 \%)$ in anti-TPO Ab positive women as compared to $\mathrm{Ab}$ negative women. Pre-eclampsia, GDM and PPH were not significantly associated with anti-TPO Ab positivity.

Authors noted a significant association between miscarriage rate $(11.54 \%$ versus $2.53 \%)$ and anti-TPO Ab positivity $(\mathrm{p}=0.042)$. The chances of IUD in anti-TPO Ab positive women were twice as compared to $\mathrm{Ab}$ negative women $(3.85 \%$ versus $1.69 \%)$ but this difference was not significant $(\mathrm{p}=0.961)$. The incidence of preterm delivery $(11.54 \%)$ was also higher in both early preterm $(3.85 \%)$ and late preterm $(7.69 \%)$ in anti-TPO Ab positive ( $p>0.05)$. PROM, fetal distress (passage of meconium), caesarean section rates, Apgar score, NICU admission and neonatal death had no significant correlation with anti-TPO Ab positivity.

Table 2: Distribution of women according to pre-pregnancy BMI.

\begin{tabular}{|lllll|}
\hline \multirow{2}{*}{ BMI $\left(\mathrm{kg} / \mathrm{m}^{2}\right)$} & \multicolumn{2}{l|}{ Anti-TPO antibody } & Negative \\
& Positive & \multicolumn{2}{l|}{} \\
\cline { 2 - 5 } & No. & Percentage & No. & Percentage \\
\hline$<18.5$ (underweight) & 1 & $3.85 \%$ & 10 & $2.11 \%$ \\
\hline 18.5 to 24.9 (Normal) & 10 & $38.46 \%$ & 367 & $77.43 \%$ \\
\hline 25 to 29.9 (Overweight) & 14 & $53.84 \%$ & 84 & $17.72 \%$ \\
\hline$>30$ (obese) & 1 & $3.85 \%$ & 13 & $2.74 \%$ \\
\hline Total & 26 & $100.00 \%$ & 474 & $100.00 \%$ \\
\hline
\end{tabular}

Table 3: Distribution of women according to complications in pregnancy.

\begin{tabular}{|c|c|c|c|c|c|c|}
\hline \multirow{3}{*}{ Pregnancy complications } & \multicolumn{4}{|c|}{ Anti-TPO antibody } & \multirow{3}{*}{ p-value } & \multirow{3}{*}{ Significance } \\
\hline & \multicolumn{2}{|c|}{ Positive $(n=26)$} & \multicolumn{2}{|c|}{ Negative $(n=474)$} & & \\
\hline & No. & Percentage & No. & Percentage & & \\
\hline Anaemia & 15 & $57.69 \%$ & 235 & $49.58 \%$ & 0.546 & NS \\
\hline GDM & 1 & $3.85 \%$ & 21 & $4.43 \%$ & 0.727 & NS \\
\hline Gestational hypertension & 2 & $7.69 \%$ & 32 & $6.75 \%$ & 0.830 & NS \\
\hline Pre-eclampsia & 1 & $3.85 \%$ & 22 & $4.64 \%$ & 0.770 & NS \\
\hline Placental abruption & 1 & $3.85 \%$ & 8 & $1.68 \%$ & 0.961 & NS \\
\hline PPH & 0 & $0.00 \%$ & 9 & $1.89 \%$ & 0.960 & NS \\
\hline
\end{tabular}


After excluding 3 miscarriages and 1 IUD, out of 22 live births 5 babies $(22.73 \%)$ were born with low birth weight $(<2.5 \mathrm{~kg})$ and 17 babies $(72.73 \%)$ were having normal birth weight $(>2.5 \mathrm{~kg})$ in anti-TPO Abs positive group.
Authors observed that irrespective of gestational age, birth weight of new-borns was significantly affected by presence of anti-TPO Ab positivity $\left(\mathrm{p}=0.013, X^{2}=6.162\right.$ and d.f.=1).

Table 4: Distribution of women according to pregnancy outcome.

\begin{tabular}{|c|c|c|c|c|c|c|c|}
\hline \multirow{3}{*}{\multicolumn{2}{|c|}{ Pregnancy outcome }} & \multicolumn{4}{|c|}{ Anti-TPO antibody } & \multirow{3}{*}{ p-value } & \multirow{3}{*}{ Significance } \\
\hline & & \multicolumn{2}{|c|}{ Positive (n=26) } & \multicolumn{2}{|c|}{ Negative $(n=474)$} & & \\
\hline & & No. & Percentage & No & Percentage & & \\
\hline Miscarriage & & 3 & $11.54 \%$ & 12 & $2.53 \%$ & 0.042 & Sig \\
\hline IUD & & 1 & $3.85 \%$ & 8 & $1.69 \%$ & 0.961 & NS \\
\hline \multirow{2}{*}{ Preterm deliveries } & $<34$ weeks & 1 & $3.85 \%$ & 10 & $2.11 \%$ & 0.921 & NS \\
\hline & 34-37 weeks & 2 & $7.69 \%$ & 22 & $4.64 \%$ & 0.812 & NS \\
\hline PROM & & 1 & $3.85 \%$ & 20 & $4.22 \%$ & 0.682 & NS \\
\hline Meconium & & 3 & $11.53 \%$ & 56 & $11.81 \%$ & 0.787 & NS \\
\hline Caesarean & & 5 & $19.23 \%$ & 108 & $21.09 \%$ & 0.619 & NS \\
\hline \multirow{2}{*}{ Apgar score } & $<7$ & 4 & $18.18 \%$ & 130 & $28.63 \%$ & \multirow{2}{*}{0.411} & \multirow{2}{*}{ NS } \\
\hline & $>7$ & 18 & $81.82 \%$ & 324 & $71.37 \%$ & & \\
\hline \multicolumn{2}{|l|}{ NICU admission } & 4 & $15.38 \%$ & 82 & $17.29 \%$ & 0.988 & NS \\
\hline \multicolumn{2}{|l|}{ Neonatal death } & 0 & $0.00 \%$ & 5 & $1.05 \%$ & 0.627 & NS \\
\hline
\end{tabular}

Table 5: Birth weight distribution of neonates.

\begin{tabular}{|lllll|}
\hline \multirow{2}{*}{ Birth weight (in kg) } & \multicolumn{2}{l|}{ Anti-TPO antibody } \\
\cline { 2 - 5 } & Positive & \multicolumn{2}{l|}{ Negative } \\
\cline { 2 - 5 } & No. & Percentage & No. & Percentage \\
\hline LBW (SGA + preterm) & 5 & $22.73 \%$ & 29 & $6.39 \%$ \\
\hline Normal birth weight & 17 & $72.27 \%$ & 425 & $93.61 \%$ \\
\hline Total & 22 & $100.00 \%$ & 454 & $100.00 \%$ \\
\hline
\end{tabular}

\section{DISCUSSION}

Thyroid disorders especially those of autoimmune origin are common in women of reproductive age group. In an unselected population of women, the prevalence ranges from $4 \%$ to $20 \%$. This study revealed the prevalence of anti-TPO Ab positivity in euthyroid women was $5.20 \%$. Similar prevalence was found by Gayathri R et al, 7\%, Meena $\mathrm{A}$ et al, 6\% and Meena $\mathrm{M}$ et al, 4\%.5-7 While higher prevalence reported by Negro $\mathrm{R}$ et al, $11.7 \%$, Karuna et al, $10.92 \%$ and Rajput $\mathrm{R}$ et al, $18.9 \% .^{8-10}$ The rates of anti-thyroid antibody positivity are varied in different studies and depend upon the sample size as well as the geographical factors of the study group.

Most of the women were in the age group of 24-27 years with mean maternal age $24.96 \pm 3.13$ years in anti-TPO Ab positive group and $24.86 \pm 3.97$ years in Abs negative group ( $\mathrm{p}=0.901$ ). Similarly, Meena A et al noted, most of women were in the age group of 25-27 years. ${ }^{6}$ Some studies reported higher mean age like Meena $\mathrm{M}$ et al, $26.95 \pm 3.809$ versus $26.38 \pm 2.826$ years, Masoomen $M$ et al, 26.7 versus 27.6 years and Karuna et al, 26.02 \pm 4.18 versus $26.29 \pm 3.99$ years in anti-TPO $\mathrm{Ab}+\mathrm{ve}$ and $\mathrm{Ab}-\mathrm{ve}$ women respectively. $6,7,9,11$ Authors observed that the mean maternal age in both groups was less as compared to Western studies, reflecting early marriage and early conception prevalent in India.

In Table 2, most of anti-TPO Ab positive women were overweight while most of $\mathrm{Ab}$ negative women were having normal weight, that was a significant association between pre-pregnancy BMI and anti-TPO positivity $(\mathrm{p}=0.000)$. Meena $\mathrm{M}$ et al, reported BMI in the anti-TPO positive subjects was $22.472(\mathrm{SD} \pm 2.81)$ while in the controls it was $21.93(\mathrm{SD} \pm 2.02){ }^{7}$ Abbassi-Ghanavati $\mathrm{M}$ et al, also reported that women who were TPO Ab positive were heavier. ${ }^{12}$ While Karakosta $\mathrm{P}$ et al, and Rajput $\mathrm{R}$ et al, observed no significant difference between the BMI and anti-TPO positivity., ${ }^{40}$

In present study authors compared various distinct fetomaternal outcomes in euthyroid women. Authors noticed the primary findings of the significant association between thyroid antibody positivity and the increased rate of miscarriages and low birth weight babies. Table 3 and 4 presents multivariate associations of thyroid autoimmunity in early pregnancy with pregnancy 
complications. Pregnancy complications like anaemia, GDM, gestational hypertension, preeclampsia, placental abruption and PPH were not significantly association with anti-TPO positivity.

The prevalence of anaemia was higher $(57.69 \%)$ in antiTPO Ab positive women than $49.58 \%$ in $\mathrm{Ab}$ negative women $(\mathrm{p}=0.546)$. As any other autoimmune disorder, the auto-antibodies may be responsible for the destruction of red blood cells along with the inflammatory process setting in. Meena M et al (2016)7 reported a significantly higher prevalence of anaemia $(52.5 \%$ versus $17.5 \%)$ in women with thyroid autoimmunity.

More than two-fold increase in incidence of placental abruption in anti-TPO $\mathrm{Ab}$ positive women compared to $\mathrm{Ab}$ negative women $(3.85 \%$ versus $1.68 \%)$ but this difference was not significant $(\mathrm{p}=0.961)$. Similarly, Abbassi-Ghanavati $\mathrm{M}$ et al, reported a 3-fold increase in placental abruption in anti-TPO Ab positive women. ${ }^{12}$

Authors reported a significant association between antiTPO Ab positivity and miscarriage rate $(\mathrm{p}=0.042)$. There were higher numbers of miscarriages, $11.54 \%$ in anti$\mathrm{TPO} \mathrm{Ab}$ positive euthyroid pregnancies than $2.53 \%$ in $\mathrm{Ab}$ negative pregnancies (Table 4). Higher chances of miscarriage could be due to subtle deficiency of thyroid hormone concentrations or a lower capacity of the thyroid gland to adapt to the demands of pregnancy in euthyroid pregnant women with TPO Ab positivity. Similar to this results, Rajput $\mathrm{R}$ et al, reported 18 (12\%) women with TPO Ab positivity and $5(3.3 \%)$ women with Ab negative status had miscarriages and the difference was statistically significant $(\mathrm{p}<0.004) .{ }^{10}$

These results were also consistent with the findings of Negro R et al and Stagnaro-Green A et al, who reported two fold increase in miscarriage rate in presence of TPO $\mathrm{Ab}(17 \%$ versus $8.4 \%, \mathrm{p}=0.011){ }^{8,13}$ Meena $\mathrm{M}$ et al, concluded against this study observations that there was no statistical significant difference in the rates of recurrent abortions between the two groups ( $8 \%$ versus $5 \%$ respectively, $\mathrm{p}$-value $=0.367) .{ }^{7}$ Recently, Masoomeh $M$ et al, reported the incidence of spontaneous miscarriage was significantly higher in anti-TPO $\mathrm{Ab}$ positive women than $\mathrm{Ab}$ negative women (19\% versus $5.7 \% ; \mathrm{p}<0.001){ }^{11}$

Authors observed in Table 3 two times more chance of IUD in anti-TPO $\mathrm{Ab}$ positive women compared $\mathrm{Ab}$ negative women $(3.85 \%$ versus $1.69 \%)$ but this difference was not significant $(\mathrm{p}=0.961)$. Mannisto $\mathrm{T}$ et al, found an increase in perinatal death in anti-TPO $\mathrm{Ab}$ positive women while Rajput $\mathrm{R}$ et al, reported no significant association $2.6 \%$ versus $2 \%, \mathrm{p}=0.5){ }^{10,14}$

In this study, the incidence of preterm delivery (11.54\%) was higher in early preterm $(3.85 \%)$ and also in late preterm $(7.69 \%)$ in anti-TPO Ab positive women as compared to total $6.75 \%$ in Ab negative women ( $p>0.05$ ).
The likely reason for higher incidence of preterm deliveries is that the presence of thyroid autoantibodies reflects a generalized activation and deregulation of the immune system against the fetal-maternal interface. Glinoer D et al, showed that the rate of preterm deliveries in women with thyroid autoimmunity almost doubled as compared to the healthy controls. ${ }^{2}$ Similarly, Negro R et al reported a significant increase in preterm delivery in thyroid antibody positive women compared to antibody negative women (22.4 versus $8.2 \%){ }^{8}$ Stagnaro-Green A et al, Tierney $\mathrm{K}$ et al and Karuna et al found no significant association between thyroid antibody positivity and preterm labour., ${ }^{9,15,16}$ Authors noticed higher no (28.63\%) of low Apgar babies were from antiTPO Ab negative women as compared to $18.18 \%$ in $\mathrm{Ab}$ positive women, that was not significant $(\mathrm{p}=0.411)$.

In Table 5 authors observed that irrespective of gestational age, birth weight of newborns was significantly affected by presence of anti-TPO Abs $(\mathrm{p}=0.013)$. Incidence of low birth weight babies was 4fold higher in anti-TPO $\mathrm{Ab}$ positive women than $\mathrm{Ab}$ negative women $(22.73 \%$ versus $6.38 \%)$. Meena $\mathrm{M}$ et al, found significant association $(\mathrm{p}<0.001)$ between antiTPO Ab status and birth weight, $25 \%$ versus $5.12 \%$ respectively in both groups. ${ }^{7}$ Meena A et al reported, rates of preterm delivery at $>34$ weeks were $5 \%$ versus $1.80 \%$ respectively in thyroid antibody positive and negative women, while preterm delivery rates between 34 and 37 weeks in both groups were $8.33 \%$ versus $3.19 \% .^{6}$

Although preterm delivery rate was more in antibody positive group, it was not significant $(\mathrm{p}>0.05)$, but there was significant difference among birth weights of newborns in both groups $(\mathrm{p}<0.001)$. Karakosta $\mathrm{P}$ et al noticed increased rates of low birth weight babies in thyroid autoimmune patient. ${ }^{4}$ Similar results were obtained by Rajput $\mathrm{R}$ et al $10 \%$ versus $5.2 \%, \mathrm{p}=0.09 .^{10}$ While, Negro R et al, reported no significant difference in low birth weight babies between the two groups $(6.5 \%$ versus $4.8 \%, \mathrm{p}=0.229) .{ }^{17}$ Abbassi-Ghanavati $\mathrm{M}$ et al also found no difference in low birth weight babies among anti-TPO antibodies positive and negative women. ${ }^{12}$

\section{CONCLUSION}

From study hospital based prospective observational study, authors concluded that prevalence of anti-TPO antibody positivity in euthyroid obstetric population is $5.2 \%$ and these antibodies are associated with adverse fetomaternal outcomes even in euthyroid women. Significant association was noted between pre-pregnancy BMI, miscarriage rates and low birth weight with antiTPO Ab positivity. It is of prime importance to screen pregnant women for thyroid autoimmunity so that timely intervention can be done, thereby complications can be prevented.

\section{Funding: No funding sources \\ Conflict of interest: None declared}


Ethical approval: The study was approved by the Institutional Ethics Committee

\section{REFERENCES}

1. Glinoer D, Riahi M, Grun JP, Kinthaert J. Risk of subclinical hypothyroidism in pregnant women with asymptomatic autoimmune thyroid disorders. J Clin Endocrinol Metab. 1994;79:197-204.

2. Glinoer D. The thyroid function during pregnancy: maternal and neonatal aspects. In: The Thyroid and Pregnancy. Beckers C, Reinwein D (Eds). Schattauer, NY, USA; 1991:35-43.

3. Korevaar TIM, Pop VJ, Chaker L, Goddijn M, Rijke $\mathrm{YB}$, Bisschop PH, et al. Dose dependency and a functional cutoff for TPO-antibody positivity during pregnancy. J Clin Endocrinol Metab. 2018;103(2):778-9.

4. Karakosta P, Alegakis D, Georgiou V, Roumeliotaki $\mathrm{T}$, Fthenou E, Vassilaki $\mathrm{M}$, et al. Thyroid dysfunction and autoantibodies in early pregnancy are associated with increased risk of gestational diabetes and adverse birth outcomes. J Clin Endocrinol Metab. 2012;97:4464-72.

5. Gayathri R, Lavanya S, Raghavan. Subclinical hypothyroidism and autoimmune thyroiditis in pregnancy- a study in south Indian subjects. JAPI. 2009;57:691-3.

6. Meena A, Nagar P. Pregnancy outcome in euthyroid women with anti-thyroid peroxidase antibodies. J Obstet Gynaecol India. 2016;66(3):160-5.

7. Meena M, Chopra S, Jain V, Aggarwal N. The effect of anti-thyroid peroxidase antibodies on pregnancy outcomes in euthyroid women. J Clin Diagn Res. 2016;10(9):QC04-7.

8. Negro R, Formoso G, Mangieri T, Pezzarossa A, Dazzi D, Hassan H. Levothyroxine treatment in euthyroid pregnant women with autoimmune thyroid disease: effects on obstetrical complications. J Clin Endocrinol Metab. 2006;91(7):2587-91.

9. Karuna, Das V, Agrawal S, Agarwal A, Pandey A, Mahdi AA. Status of thyroid peroxidase antibodies in pregnant women and association with obstetric and perinatal outcomes in tertiary care center. Nat $\mathbf{J}$ Laboratory Med. 2017;6(4):BO17-BO21.
10. Rajput R, Yadav T, Seth S, Nanda S. Prevalence of thyroid peroxidase antibody and pregnancy outcome in euthyroid autoimmune positive pregnant women from a tertiary care center in Haryana. Indian $\mathbf{J}$ Endocrinol Metab. 2017;21(4):577-80.

11. Masoomeh M, Ahia KA, Jamali M, Ebrahimi A, Mahya V. Effect of antithyroid peroxidase antibody on pregnancy outcome in euthyroid women. Perinatol. 2019;20(1):10-5.

12. Abbassi-Ghanavati M, Casey BM, Spong CY, McIntire DD, Halvorson LM, Cunningham FG. Pregnancy outcomes in women with thyroid peroxidase antibodies. Obstet Gynecol. 2010;116(2 Pt 1):381-6.

13. Stagnaro-Green A, Roman SH, Cobin RH, El-Harazy E, Alvarez-Marfany E, Davies TF. Detection of atrisk pregnancy by means of highly sensitive assays for thyroid autoantibodies. J Am Med Associat. 1990;264(11):1422-5.

14. Mannisto T, Vaarasmaki M, Pouta A, Suvanto E. Thyroid dysfunction and autoantibodies during pregnancy as predictive factors of pregnancy complications and maternal morbidity in later. Life $\mathbf{J}$ Clin Endocrinol Metab. 2010;95(3):1084-94.

15. Stagnaro-Green A, Chen X, Bogden JD, Scholl TO. The thyroid and pregnancy: a novel risk factor for very preterm delivery. Thyroid. 2005;15:351-7.

16. Tierney K, Delpachitra P, Grossmann M, Onwude J, Tong S. Thyroid function and autoantibody status among women who spontaneously delivery under 35 weeks of gestation. Clin Endocrinol (Oxf). 2009;71:892-5.

17. Negro R, Schwartz A, Gismondi R, Tinelli A, Stagnaro-Green A. Thyroid antibody positivity in the first trimester of pregnancy is associated with negative pregnancy outcomes. J Clin Endocrinol Metab. 2011;96(6):E920-4.

Cite this article as: Netra HK, Pant R, Banerjee KP. observational study of fetomaternal outcome in euthyroid women with anti-thyroid peroxidase antibodies at tertiary care hospital. Int J Reprod Contracept Obstet Gynecol 2020;9:2476-81. 